\title{
The Carnegie Curve
}

\author{
R. Giles Harrison
}

Received: 16 July 2012/Accepted: 17 October 2012/Published online: 12 December 2012

(C) Springer Science+Business Media Dordrecht 2012

\begin{abstract}
The Earth's fair weather atmospheric electric field shows, in clean air, an average daily variation which follows universal time, globally independent of the measurement position. This single diurnal cycle variation (maximum around 19UT and minimum around 03UT) is widely known as the Carnegie curve, after the geophysical survey vessel of the Carnegie Institution of Washington on which the original measurement campaigns demonstrating the universal time variation were undertaken. The Carnegie curve's enduring importance is in providing a reference variation against which atmospheric electricity measurements are still compared; it is believed to originate from regular daily variations in atmospheric electrification associated with the different global disturbed weather regions. Details of the instrumentation, measurement principles and data obtained on the Carnegie's seventh and final cruise are reviewed here, also deriving new harmonic coefficients allowing calculation of the Carnegie curve for different seasons. The additional harmonic analysis now identifies changes in the phasing of the maximum and minimum in the Carnegie curve, which shows a systematic seasonal variation, linked to the solstices and equinoxes, respectively.
\end{abstract}

Keywords Atmospheric electricity · Global circuit · Potential gradient · Universal diurnal variation

Electronic supplementary material The online version of this article (doi:10.1007/s10712-012-9210-2) contains supplementary material, which is available to authorized users.

R. G. Harrison $(\bowtie)$

Department of Meteorology, University of Reading, P.O. Box 243, Earley Gate,

Reading RG6 6BB, UK

e-mail: r.g.harrison@reading.ac.uk 


\section{Introduction}

The discovery ${ }^{1}$ that an electric field persists in the atmosphere in fair weather, ${ }^{2}$ in the absence of local thunderstorms, immediately posed the question of how it originated. Investigations into fair weather electrification continued during the late eighteenth century and nineteenth century, but major advances in understanding atmospheric electricity, however, remain inextricably linked with the name of the Carnegie, an early twentiethcentury geophysical survey ship operated by the Carnegie Institution of Washington (Fig. 1). The Carnegie made hourly measurements of the atmospheric electric field in oceanic air, during four major global cruises. This review seeks to describe the historical context and scientific developments underpinning the Carnegie's atmospheric electricity measurements, as they are still widely used. The original data are also provided in an accessible digital form, allowing analysis beyond that of the original reports.

During the first quarter of the twentieth century, the Carnegie Institution of Washington operated the Galilee and Carnegie as geophysical survey ships. Both were sailing vessels constructed of wood, allowing geomagnetic measurements to be undertaken. Overall, seven major cruises were undertaken by the Carnegie, between 1909 and 1929 which, together with atmospheric electricity observations, returned magnetic and oceanographic surveys $^{3}$ and studies of the marine biology, physics and chemistry.

Preliminary atmospheric electricity measurements were made on the final cruise of the Galilee (August 1907) which continued on Cruises I, II and III of the Carnegie (1909-1914). Cruise IV (1915-1917) of the Carnegie was the first voyage well-equipped for atmospheric electricity work. For the atmospheric electricity measurements, the Carnegie's scientific team had to pioneer new methods and instruments. At the first trials in 1907, obtaining any reliable measurements of the atmosphere's electric field ${ }^{4}$ over the oceans seemed insurmountable due to ship motion, sail changes and the need for highquality insulation despite spray and damp, but, by the seventh cruise in 1928/1929, the techniques had improved so substantially that their goal of continuous recording ${ }^{5}$ of the atmosphere's electric field over the sea was reached. Analysis of the results from Cruise VII confirmed the important result that the daily electric field variation in universal time was independent of the ship's position. A similar variation had been seen previously using the more intermittent manually recorded data from Cruises IV, V and VI (Mauchly 1921, 1923). This diurnal variation is a key part of the contemporary understanding of global atmospheric electricity (Aplin et al. 2008) and is generally known as the Carnegie curve,

\footnotetext{
1 Experiments clearly demonstrating fair weather electrification occurred during the summer of 1753 in England and France (Harrison 2011a), supporting the view of Lemonnier (1752) that the electrification arose from the air rather than the Earth.

${ }^{2}$ Fair weather conditions are those in which no local electrification processes are occurring, without appreciable convective cloud extent. (In early literature, such weather conditions were also described as serene.)

3 Oceanographic studies of the Carnegie contributed particularly to understanding the deep water of the Pacific and flow in the north Pacific, notably through the work of Roger Revelle and Harald Sverdrup.

4 Throughout, the atmospheric electric field will be described as the Potential Gradient (PG). For a vertical electric field $E_{\mathrm{z}}$, the $\mathrm{PG}$ is given by $-E_{\mathrm{z}}$; the $\mathrm{PG}$ is positive in fair weather.

${ }^{5}$ Continuous photographic recording was long established at land observatories. Lord Kelvin argued in September 1859 for "incessant" recording of the atmospheric electric field using such methods (Thomson 1859). [Lord Kelvin (William Thomson, 1824-1907) was President of the Royal Society and an outstanding classical physicist. In 1860, he suggested that the potential gradient's sensitivity to environmental conditions might prove useful "...for prognosticating the weather."].
} 


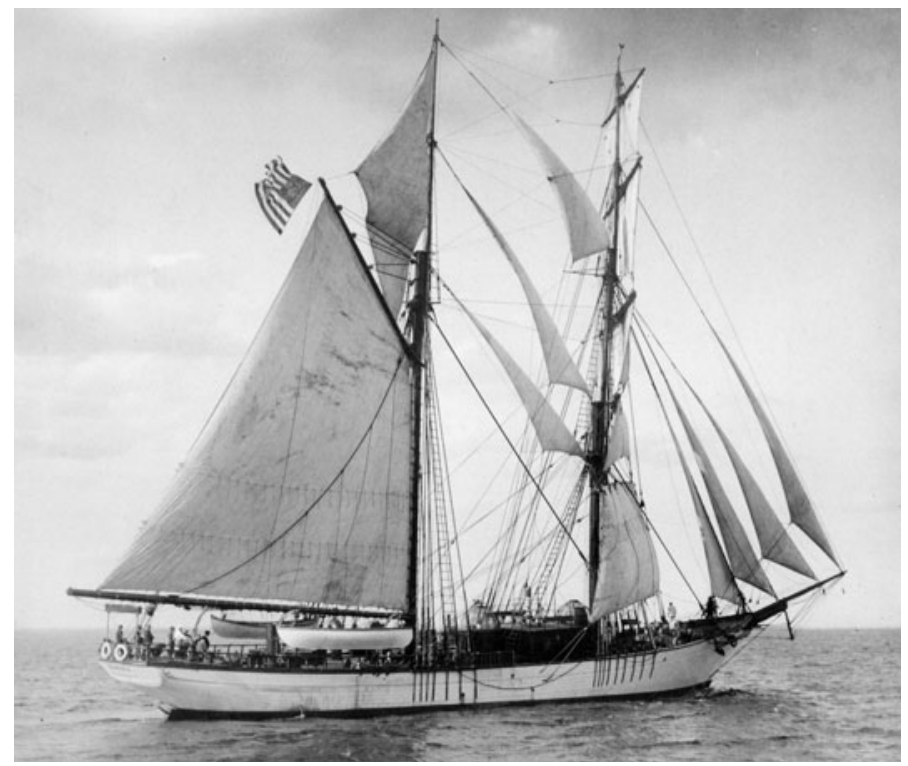

Fig. 1 The Carnegie under full sail, in 1909 (Carnegie Institution of Washington, Department of Terrestrial Magnetism)

against which modern studies are still compared (e.g., Mach et al. 2011; Rodger et al. 2006).

Although further measurement campaigns had been planned for the Carnegie, Cruise VII sadly became its last, as the ship and all her equipment were destroyed in a petrol explosion at Apia (Samoa), on 28 November 1929. Both the ship's master, Captain J. P. Ault, and a cabin boy died in the disaster, with five others injured. Only a few months earlier (26 August 1929), in addressing a commemorative event for the Carnegie in San Francisco, Captain Ault had remarked ${ }^{6}$ that "The story of individual endeavour and enterprise, of invention and accomplishment, cannot be told." Whilst his own demise with the Carnegie of course brought a tragic end to these endeavours, some of the great accomplishments of the ship's staff are nevertheless immortalised through the many research publications of the Carnegie Institution of Washington (e.g., Bauer et al. 1917; Torreson et al. 1946). ${ }^{7}$

The purpose of this paper is to provide, almost a century later, a modern summary of the methods with which the Carnegie curve was obtained, and is accordingly confined to the Carnegie's potential gradient (PG) data, reproduced digitally in the Electronic Supplementary Material (ESM). The many other ocean air atmospheric electricity measurements made on the Carnegie, for example, of air conductivity, have themselves proved useful in studies of long-term pollution changes (Cobb and Wells 1970), as may yet the ocean air ion production rates measured during solar cycles 15 and 16, before the cosmic ray reduction associated with the grand solar maximum of the second half of the twentieth century (Owens et al. 2012). But, as no similarly extensive and thorough global surveys have been

\footnotetext{
${ }^{6}$ Carnegie Institution of Washington Publication 568, page iii.

7 These will be referred to using the abbreviated form "CIW", adding volume numbers and pagination as appropriate. They are now available in digitised form at http://archive.org/details/carnegieinstitution.
} 
conducted-in part, perhaps, due to the loss of the research ship which would have undertaken at least some of them - this early PG data in particular retain its importance to the study of fair weather atmospheric electricity and the modern synthesis provided by the global circuit concept (Rycroft et al. 2000). In digital form, the Carnegie data source is now amenable to modern analysis, such as in considering the statistical variability not evaluated in the original study, and for seasonal analysis of the data.

\section{Historical Background}

\subsection{Early Atmospheric Electricity Measurement Technology}

Early measurements of the atmospheric potential over land used an insulated electrode exposed to the atmosphere above the surface, connected to a mechanical electrometer to allow the extent of the electrification to be found (Harrison 2004a; Nicoll 2012). The sensing electrode or "collector" used to acquire the air's local electric potential was initially typically a flame or elevated point (Harrison 2004a). Electrometers of the eighteenth and nineteenth centuries employed electrostatic repulsion, such as with pith balls (Read 1792) or the deflection of straws or fibres (Hackmann 1994).

In 1860, Lord Kelvin described a "water dropper" collector system (Everett 1868), which consisted of an insulated tank continuously generating a spray of water. At the point where the water broke into drops, the spray transferred charge into the air until its potential became equal with the local potential of air. This was found by measuring the potential of the tank that was measured with respect to Earth, and a continuous chart record could be obtained photographically. Although in principle this provided an absolute method for determining the air potential at the spray generation point (and, therefore, the vertical potential gradient between this point and Earth), Kelvin was aware that the effect of an electrode could be to distort the local field being measured (Thomson 1859). To determine the geometrical correction, measurements without field distortion can be obtained by using a plate electrode, mounted flush with, but insulated from, level ground. Such an implementation was ultimately used at the Kew Observatory site near London (Harrison 2003; Harrison and Ingram 2005) with a procedure devised by Wilson ${ }^{8}$ (1906), near to the Kelvin water dropper recording system.

Balloon-carried measurements of atmospheric electricity parameters began in the late nineteenth century and also employed water dropper technology (Harrison and Bennett 2007; Nicoll 2012). For the measurement of air conductivity, ${ }^{9}$ an aspirated tubular sensor was developed (Gerdien 1905). This consisted of a well-insulated central electrode, mounted concentrically with an outer tubular electrode (see Nicoll 2012, Figure 5). After charging the central electrode to a known potential, air was drawn through the tube by a fan, and the rate of decay of the central electrode voltage measured. This allowed the air conductivity to be found (e.g., Aplin 2005). An additional feature of the "Gerdien tube"

\footnotetext{
${ }^{8}$ Charles Thomas Rees Wilson (1869-1959) was a Scottish atmospheric physicist and winner of the 1927 Nobel Prize for physics, for the invention of the cloud chamber (see also Harrison 2011b).

9 Air has a finite electrical conductivity because of the constant generation of molecular cluster ions, from natural radioactivity and cosmic rays. The conductivity of air is proportional to the number concentration of molecular cluster ions present and their mobility. Air's electrical conductivity is a very variable quantity as cloud droplets or aerosol particles, which show strongly fluctuating concentrations in atmospheric air, modulate the conductivity by removing ions.
} 
was that its outer electrode provided some electrostatic and physical shielding of its sensitive inner electrode.

The first PG measurements aboard a ship at sea seem likely to have been those of Exner, made between Aden and Bombay in 1888 (Simpson and Wright 1911). Clearly, the approach of using a flush-mounted plate electrode over undistorted ground was unsuitable for use on board ship. However, the need to correct for the field distortion was, if anything, even more acute than over land, as, for sailing ships, almost every location on board was strongly influenced by the presence of yards, sails and ropes, whose positions constantly changed. Realising this, in the pioneering marine PG observations of Simpson and Wright (Simpson and Wright 1911) on the Terra Nova during 1910, measurements made on board the ship were calibrated to additional measurements determined over a level beach. This site was 1,000 yards from the ship, where a long $(18 \mathrm{~m})$ fine horizontal wire, well insulated at each end, had been arranged. Because of its very small cross-section, and the substantial distance between the mounting posts, the long fine wire "antenna" provided minimal field distortion and, therefore, reference PG values.

The ratio of the ship-measured PG to the beach-measured PG provided the geometrical correction for field distortion, known as the reduction factor, which, once determined, could be applied to the ship PG measurements if the sail and rigging geometry remained unchanged. (The reduction factor remains a fundamental consideration for all PG measurements, in which placement of a sensor distorts the local field; see, for example, Bennett and Harrison 2006.)

One further aspect of the Terra Nova and the earlier measurements of Simpson ${ }^{10}$ in Lapland (Simpson 1906) was that the collector used was coated with radioactive material. This enhanced the local ionisation and, therefore, the air's local conductivity, increasing the rate at which the collector acquired the air potential, giving better time resolution.

\subsection{Origin of the Carnegie Oceanic Atmospheric Electricity Measurements}

Inspiration to include atmospheric electricity amongst the Carnegie Institution's measurements can be traced back to the German scientists J. Elster and H. Geitel, ${ }^{11}$ when plans for the ocean magnetic surveys were being developed. As magnetic and atmospheric electricity measurements had long often been combined, such as at Kew Observatory in the UK (Ronalds 1847; Harrison 2003), Elster and Geitel may even have expected that atmospheric electricity measurements would be made alongside the magnetic observations. They made their aspiration for the inclusion of atmospheric electricity measurements clear in a letter ${ }^{12}$ to the Carnegie Institution written on 26 January 1902:

...we beg leave to suggest that it would be in full harmony with the proposed plan to combine with the organization of international magnetic work also the inauguration of observations pertaining to the electric condition of the Earth and of the atmosphere...

\footnotetext{
${ }^{10}$ Sir George Simpson (1878-1965) travelled on the Terra Nova as meteorologist on the tragic British Antarctic Expedition led by Captain Robert Falcon Scott, and was later director of the Met Office (1920-1938).

11 Julius Elster (1854-1920) and Hans Geitel (1855-1923) worked together at a secondary school in Wolfenbüttel, which allowed them time for research, notably in atmospheric electricity and radioactivity. Simpson (1906) acknowledges Elster and Geitel's work in evaluating rods coated with radioactivity as a suitable collector for Antarctic use.
}

12 CIW175v3, p362. 
In response, the Carnegie Institution Director, Dr. L. Bauer, ${ }^{13}$ visited Europe in spring 1903, meeting, as well as Elster and Geitel, other key researchers in atmospheric science (notably von Bezold, Chree, Ebert, Mascart, Schuster, Shaw, Rucker and Wiechert). Initially, it was not thought wise to embark on ocean atmospheric electricity work until the basic problems of accurate oceanic magnetic work were solved, so preliminary atmospheric measurements were delayed until the third and final cruise of the Galilee. These did not prove at all easy; in fact, it was reported ${ }^{14}$ that PG measurements

...seemed quite impracticable...the rolling of the ship, the flapping of the sails, and the varying position of the yards and boom under various sailing conditions all contributed to make the problem of reducing observations of potential-gradient to a uniform basis too complicated...

Of several atmospheric electricity instruments originally considered for evaluation on the Galilee, only air conductivity measurements, using the Gerdien aspirated device (Gerdien 1905), apparently showed any promise for ocean measurements. Air ion measurements continued to be made on Cruise I of the Carnegie (1909-1910), alongside observations of "specific conductivity" and "radioactive content".

On the Carnegie's second cruise (1910-1913), as well as continuing with conductivity and radioactivity measurements, PG measurements were attempted again. Radioactive collectors were used with a mechanical electrometer, with the collectors suspended on a bamboo pole extending back from the ship's stern rail. A similar method was used on Carnegie Cruise III (8 June 1914 to 21 October 1914, between Brooklyn, Hammerfest, Reykjavik and Brooklyn), supporting an ionium ${ }^{15}$ collector from the rear of the ship. By making simultaneous ship and shore observations, at Reykjavik and Gardiners Bay, a correction for the electrostatic distortion due to the ship's structure, known as the reduction factor, was obtained. This allowed the PG measurements for the whole of Cruise III to be calibrated, giving the average for the cruise as $93 \mathrm{Vm}^{-1}$.

\subsection{Cruises IV, V and VI}

During Cruises IV (March 1915 to March 1917), V (December 1917 to June 1918) and VI (October 1919 to November 1921), improvements in the instruments and methods were made steadily, with increasing attention to obtaining diurnal variation results. An "atmospheric-electric house" was built aboard for Cruise IV, to protect the instruments and provide stable operating conditions, but it also minimised the setting-up time for measurements. However, the PG instrumentation, using the ionium-coated collector extended on a bamboo pole, was found increasingly unsatisfactory for regular measurements, as the collector required at least $2 \mathrm{~min}$ for the electrometer to reach $1 \mathrm{~V}$ of its final steady potential. This led to a fundamentally new design of collector, employing a sensing surface reminiscent of an open parasol (Fig. 2). This collector was made from wire gauze, arranged on a horizontally projecting pivot arm. In use, it was rotated from pointing downwards ("zero") to a horizontal measurement position, during which the associated

\footnotetext{
13 Louis Bauer (1865-1932; http://library.gl.ciw.edu/ocean/background/bauer.html) championed international cooperation in geomagnetism and founded the journal Terrestrial Magnetism in 1896, subsequently becoming Terrestrial Magnetism and Atmospheric Electricity, and later the Journal of Geophysical Research.

14 CIW175v3, p364.

15 Thorium-232.
} 
(a)

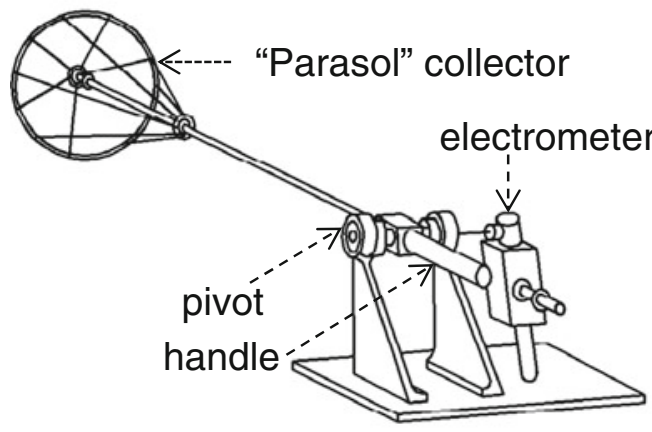

(b)

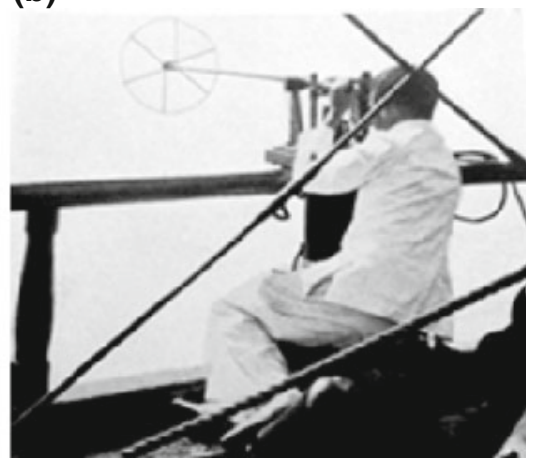

Fig. 2 a Schematic of the potential gradient measurement apparatus designed during Cruise IV, mounted at the rear of the ship. The sensing "parasol" was raised from pointing downwards to horizontal using an insulated handle, and the change in the adjacent mechanical electrometer's reading recorded. b PG apparatus in use, with the electrometer being observed by eye (Carnegie Institution of Washington, Department of Terrestrial Magnetism)

change in electrometer reading was recorded. The operating position could be adjusted for the tilt of the ship. A further advantage of measuring just the change in the electrometer reading was that the insulation requirements were reduced, with a sulphur main insulator entirely satisfactory, as long as the hard rubber insulation for the handle was kept clean with fine emery cloth. Even so, each morning the observer tested the apparatus for leakage with a $100 \mathrm{~V}$ Zamboni pile. It was also found that the ship's rail made it unnecessary to use a wire screen to eliminate inductive effects associated with movements of the observers.

Standardisation of the measurements on the ship to open surface measurements was achieved by using simultaneous observations at sea and on land. These comparison sites were chosen to be close to level with the sea and free from trees, with a horizontal passive wire antenna of 15-20 m long employed as the reference measurement. Satisfactory sites were hard to find; however, as there were difficulties in maintaining the ship's mooring within half a mile, the reduction factor was originally measured only for short periods (minutes) and averaged. Later, these standardisation experiments were extended to durations of a few hours, with the linearity between the two sets of measurements demonstrated before deriving the reduction factor. A further complication was the distortion of the electric field by changes in the arrangement of the ship's sails. The PG measurements were only made when the mainsail was up with the boom to port or starboard, or when mainsail down and the boom positioned "some 2 feet over the port crutch". These differences were quantitatively important, as apparent from the range of final values ${ }^{16}$ of the reduction factor used for 1915-1921, which varied from 2.85 (mainsail up and boom to port or starboard) to 3.77 (mainsail down and boom 2 feet over port crutch). Because changes in reduction factor affected the final values derived by the same proportional amount, they were allowed for in the results by recording the state of the sails and boom.

By the end of Cruise V, the parasol collector had become badly corroded, so the apparatus was entirely rebuilt, also implementing a stronger support rod. This arrangement ("PG2") was made to similar dimensions to keep the reduction factor the same. Reduction

${ }^{16}$ CIW175v5, p209. 


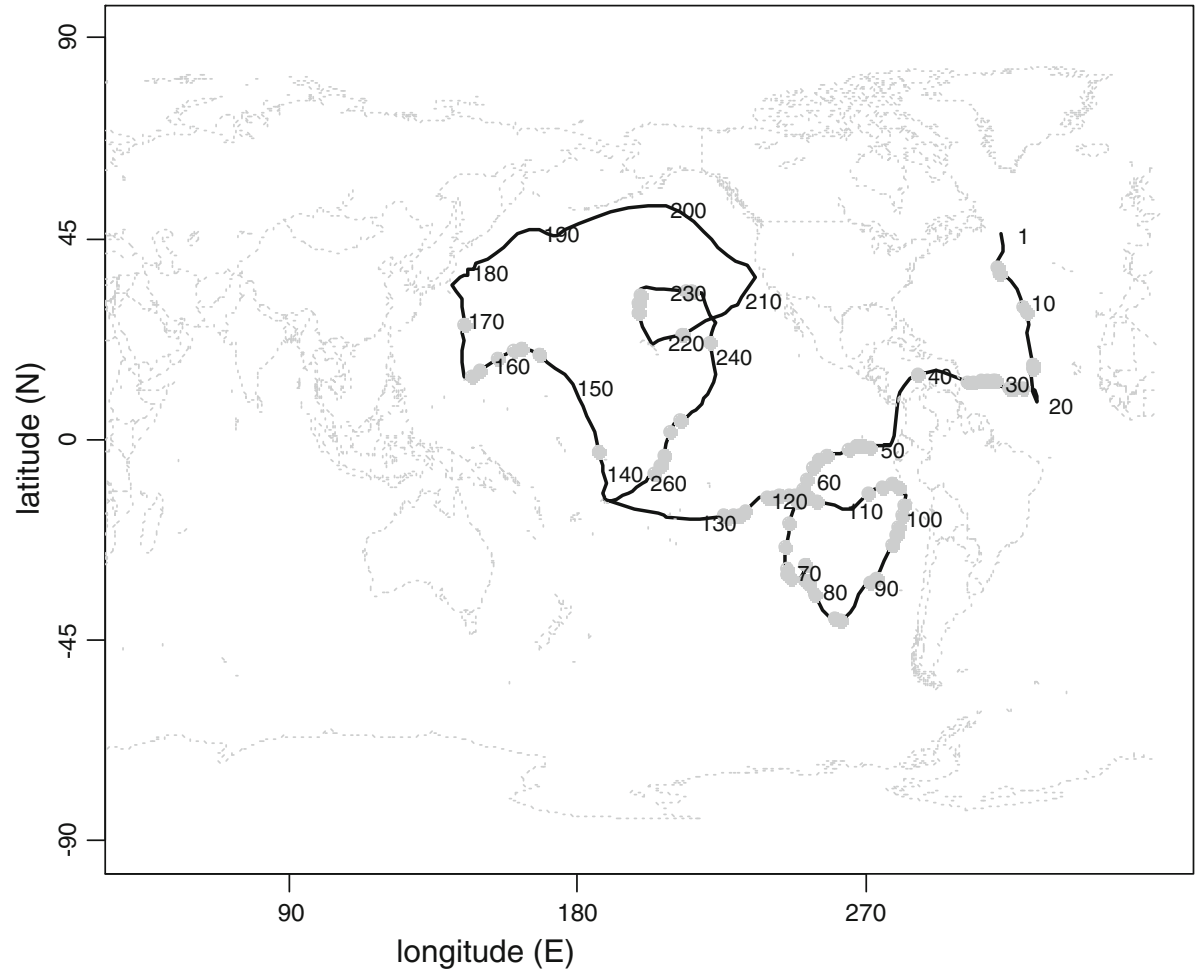

Fig. 3 Route of Cruise VII of the Carnegie. The number of days of measurements from the outset on 7 August 1928 ("cruise days") is given (see also Table 1, Fig. 5 and the Electronic Supplementary Material); those days subsequently selected as electrically undisturbed and used for calculation of the diurnal variation are marked with grey points

factors for PG2 were first made in Colon Harbor (at the entry to the Panama Canal) on 2 April 1915, and applied retrospectively to the data from the first year of Cruise IV. Further tests after Cruise VI on nonlinearities in the reduction factor found no variation, and it was said to be "practically constant", for PG from 120 to $480 \mathrm{Vm}^{-1}$.

By 1921, analysing the relative variations from the previous decade's cruises, it was very clear that the chief contribution to the diurnal variation of PG was the $24 \mathrm{~h}$ component, and, further, that, as reported by its discoverer, the Carnegie Institution's scientist S. J. Mauchly, ${ }^{17}$

...the 24 hour Fourier wave was at the great majority of land stations in practical phase agreement on universal time with the prime daily wave over the oceans without regard to location. ${ }^{18}$

\footnotetext{
${ }^{17}$ Sebastian John Mauchly (1878-1928; Obituary: Nature 123, 215-215, doi: 10.1038/123215a0), Carnegie Institution Scientist from 1914.

${ }^{18}$ CIW175v5, p387.
} 
Table 1 Dates and destinations of the Carnegie during cruise VII

\begin{tabular}{|c|c|}
\hline Dates & Location \\
\hline 10 May to 18 June 1928 & Newport News (Virginia, USA) to Plymouth (England) \\
\hline 7 to 20 July 1928 & Hamburg (Germany) to Reykjavik (Iceland) \\
\hline 27 July to 16 September 1928 & Reykjavik (Iceland) to Barbados (West Indies) \\
\hline 1 to 11 October 1928 & Barbados (West Indies) to Balboa (Panama) \\
\hline 25 October 1928 to 14 January 1929 & Balboa (Panama) to Callao (Peru) \\
\hline 5 February to 1 April 1929 & Callao (Peru) to Pago Pago (American Samoa) \\
\hline 20 April to 6 June 1929 & Apia (Samoa) to Yokohama (Japan) \\
\hline 3 to 23 September 1929 & San Francisco (California, USA) to Honolulu (Hawaii, USA) \\
\hline 2 October to 18 November 1929 & Honolulu (Hawaii, USA), to Pago Pago (American Samoa) \\
\hline
\end{tabular}
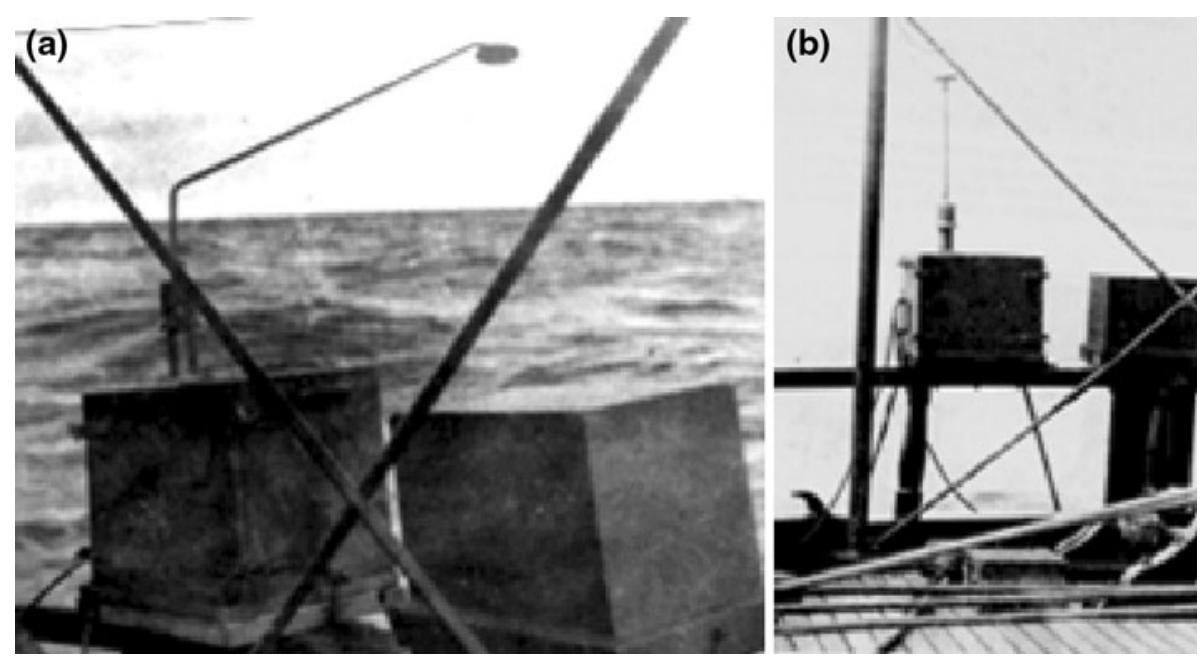

Fig. 4 Arrangement of the radioactive collector used for continuous recording on Cruise VII. The collector consisted of a circular metal plate supporting, on its underside, four small metal discs coated with ionium. The geometry of the collector's support rod was changed during the cruise. a A bent support rod was used first, projected over the water directly at the stern, used from 7 July 1928 to 5 November 1929 . b A vertical support for the collector was installed on 5 November 1929, supporting the collector $75 \mathrm{~cm}$ above a weatherproof wooden box housing the recording apparatus. (Carnegie Institution of Washington, Department of Terrestrial Magnetism)

\section{Potential Gradient Measurements on Cruise VII}

Despite the apparent robustness of Mauchly's result from the early cruises (Mauchly 1921, 1923), further frequent and widely distributed varying atmospheric electricity measurements were still sought, and Cruise VII presented the opportunity, "...to settle the question whether such variations progress on the basis of universal time" (Ault 1927). A key development from the earlier cruises was the intention to employ continuous recording techniques, ${ }^{19}$ using photographic chart recording. Table 1 summarises the progression of Cruise VII, and Fig. 3 shows, geographically, the route taken.

${ }^{19}$ CIW568, preface, iii. 


\subsection{Potential Gradient Instrumentation}

Originally, the field sensor and its photographic recorder were intended to be located at the mast head. During the first part of the cruise (May and June 1928), this was found to be impractical, as, when the sail was put to starboard, the recorder box's guy lines slackened, due to elasticity in the hemp rigging. The top of the atmospheric electrical house was not considered a suitable alternative, so, at Hamburg, an installation was arranged adjacent (starboard) to the existing manual (PG2) instrumentation which remained on the stern rail (Fig. 4a). A disadvantage was the loss of measurements whenever the ship's engine was running. The top of the collector consisted of a circular metal plate supporting, on its underside, four small radioactively coated discs. Initially (7 July 1928 to 5 November 1929), an angled support rod was used for this, allowing the sensor to be projected out over the water, but, because it twisted in rough weather, a vertical support rod later replaced it (5 November 1929). This supported the collector at $75 \mathrm{~cm}$ above the weatherproof wooden box housing the photographic recording apparatus (Fig. 4b). The support rod was fixed into an electrically heated amber insulator, protected from rain by a conical metal cap.

The photographic recording electrometer system was manufactured by Günther and Tegetmeyer, consisting of a Wulf bifilar fibre electrometer, a projection microscope, and recording box containing a motorised photographic paper roll and marking clock. The deflections of the electrometer measuring fibres were illuminated by a $110 \mathrm{~V}$ lamp, with their image projected onto a section of bromide photographic paper, as it was transported from an unexposed roll to a storage roll. The image on the photographic paper provided a chart record of the electrometer's variations. Paper rolls of $150 \mathrm{~cm}$ length were found sufficient for a week's record, allowing $5 \mathrm{~cm}$ between daily records.

Many problems were still encountered. The list is substantial and indicates great experimental diligence and resourcefulness, but the principal difficulties overcome included damp weather (affecting the PG2 insulators), instability of the electrometer fibres from pitch and roll of the ship and flapping of the sails, interactions with the nearby recording system of operating PG2 manually, a loose lens in the photographic system, photographic paper transport difficulties and overheating of an electromagnet scorching the amber insulator. Other practical concessions became necessary, such as ${ }^{20}$

In order to shelter the helmsman from the fierce tropical sun, frequently it has been necessary to stretch an awning over the stern.

which also interfered with the measurements. All these factors conspired to limit the number of fair weather days' data eventually obtained, quite apart from the weather conditions themselves. One of the longest recognised inconveniences in fair weather atmospheric electricity measurements, spiders (Read 1792), added their unique contribution to lost hours of data by spinning webs in the cap of the shore electrometer and across the supporting insulators of the stretched wire during the calibration experiments.

${ }^{20}$ CIW568, p37. 


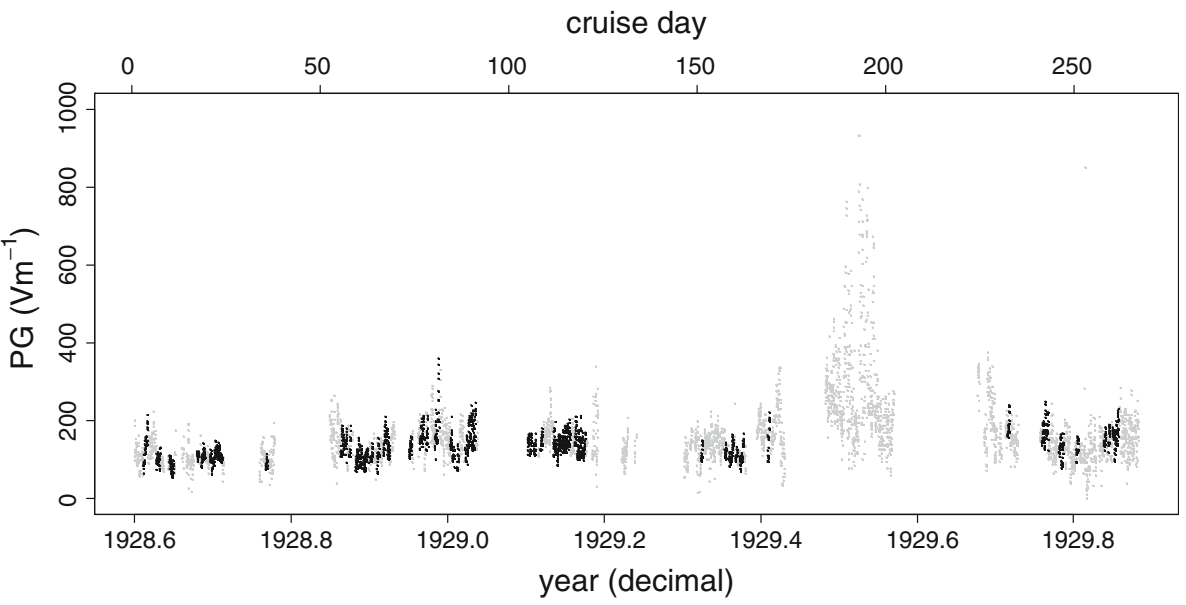

Fig. 5 Time series of all hourly PG measurements obtained (grey points) throughout Cruise VII, with the measurements made on the 82 days selected as having undisturbed conditions are marked in black

Table 2 Total number and proportion of fair weather days selected on Cruise VII, by month

\begin{tabular}{lllllllllllll}
\hline Year/month & Jan & Feb & Mar & Apr & May & June & July & Aug & Sept & Oct & Nov & Dec \\
\hline 1928 & & & & & & & & 6 & 9 & 1 & 12 & 9 \\
1929 & 8 & 12 & 5 & 1 & 7 & 0 & 0 & 0 & 1 & 6 & 5 & \\
Proportion & $10 \%$ & $15 \%$ & $6 \%$ & $1 \%$ & $9 \%$ & $0 \%$ & $0 \%$ & $7 \%$ & $12 \%$ & $9 \%$ & $21 \%$ & $11 \%$ \\
\hline
\end{tabular}

\subsection{Standardisation}

Standardisation of the ship-borne PG measurements against shore measurements ${ }^{21}$ was essential to the absolute calibration of the results, and so the reduction factor required for this conversion was measured whenever possible. A stretched horizontal wire system on a land site was used to determine the undistorted "reference" PG. These determinations were made throughout Cruise VII, at Kitts Point, Maryland (5 May 1928), Engey Island, Reykavik (25 July 1928), Bridgetown, Barbados (28-29 September 1928), Easter Island (9-10 December 1928) and Apia, Samoa (10-13 April 1929). The first two standardisations yielded reduction factors which were applied to the eye-reading instrument (PG2), and the others were used with the continuous recorder system.

\subsection{Summary of Measurements Obtained}

From 7 August 1928 to 18 November 1929, the ship was on open sea for 317 days, yielding 181 days with complete $22 \mathrm{~h}$ records of PG obtained, although, for a few of

\footnotetext{
21 A short period of the September 1928 measurements in the Atlantic has since also been found to correlate with land measurements at the UK Observatories of Eskdalemuir (Scotland) and Lerwick (Shetland), (Harrison 2004b).

${ }^{22}$ CIW 568, p113 adds, in the preamble to Table 3 "Values have been interpolated for periods of 1-3 h only on days regarded as particularly quiet and undisturbed. No interpolation has been done over periods of bad weather."
} 
Table 3 Total number and proportion of fair weather days selected on Cruise VII, by season

\begin{tabular}{|c|c|c|c|c|c|c|}
\hline \multirow{2}{*}{$\begin{array}{l}\text { Season } \\
\text { (northern } \\
\text { hemisphere) }\end{array}$} & \multicolumn{3}{|c|}{ Original season selection } & \multicolumn{3}{|c|}{ Conventional season selection } \\
\hline & $\begin{array}{l}\text { Months } \\
\text { selected }\end{array}$ & $\begin{array}{l}\text { Number of fair } \\
\text { weather days }\end{array}$ & $\begin{array}{l}\text { Proportion } \\
\text { of data }(\%)\end{array}$ & $\begin{array}{l}\text { Months } \\
\text { selected }\end{array}$ & $\begin{array}{l}\text { Number of fair } \\
\text { weather days }\end{array}$ & $\begin{array}{l}\text { Proportion } \\
\text { of data }(\%)\end{array}$ \\
\hline Winter & NDJ & 34 & 41 & DJF & 29 & 35 \\
\hline Spring & FMA & 18 & 22 & MAM & 13 & 16 \\
\hline Summer & MJJ & 7 & 9 & JJA & 6 & 7 \\
\hline Autumn & ASO & 23 & 28 & $\mathrm{SON}$ & 34 & 41 \\
\hline
\end{tabular}

these days, the data for 1 or $2 \mathrm{~h}$ were completed by interpolation. From those days, 82 days were chosen as having the least electrically disturbed conditions, for studies of the diurnal variation. This selection ${ }^{23}$ did not consider meteorological conditions (clouds, temperature, humidity, barometric pressure or atmospheric pollution). A time series of the measurements obtained, with the undisturbed days highlighted, is given in Fig. 5.

It is clear that the distribution in the days selected shows some unevenness in the sampling across the months as a result, summarised in Table 2, which persists even if the days are grouped by season (Table 3). Using either the original groupings of months (winter November-December-January, spring February-March-April, summer May-JuneJuly, and autumn August-September-October), or those more conventionally applied in modern work (winter December-January-February, spring March-April-May, summer June-July-August, and autumn September-October-November), the northern hemisphere summer was the least well sampled. Autumn and winter were much better sampled in comparison, their relative importance depending on the actual definition of seasons used.

\section{Data Analysis}

\subsection{Mean Diurnal Variations}

The hourly values of PG on days selected as undisturbed were averaged to obtain the diurnal variation. Figure 6a shows the annual diurnal variation, calculated from the undisturbed days' data as tabulated in the ESM, including the interpolated values when present, and with confidence limits derived for the mean hourly values. These clearly show that the maximum and minimum are statistically distinct. The Carnegie Institution scientists made a Fourier representation of this data, to evaluate the relative contribution of the 12 and $24 \mathrm{~h}$ variations to the diurnal cycle in PG, according to

$$
\begin{aligned}
F(t) & =A_{0}+A_{1} \sin \left(\frac{t}{24} 360^{\circ}+\phi_{1}\right)+A_{2} \sin \left(\frac{2 t}{24} 360^{\circ}+\phi_{2}\right)+A_{3} \sin \left(\frac{3 t}{24} 360^{\circ}+\phi_{3}\right) \\
& +A_{4} \sin \left(\frac{4 t}{24} 360^{\circ}+\phi_{4}\right)
\end{aligned}
$$

where $F$ is the PG at time $t$ (in hours UT). In Eq. (1), $A_{0}$ represents the mean value, and $A_{1}$ to $A_{4}$ identify the amplitude of the $24,12,8$ and $6 \mathrm{~h}$ individual harmonic components,

\footnotetext{
23 Subsequently, the need to identify fair weather conditions meteorologically became more widely recognised. For example, from 1 May 1964, the UK Met Office defined 'fair weather' conditions as those without hydrometeors, with no low stratus cloud, less than three-eighths cumuliform cloud and a mean hourly wind speed of less than $8 \mathrm{~ms}^{-1}$.
} 

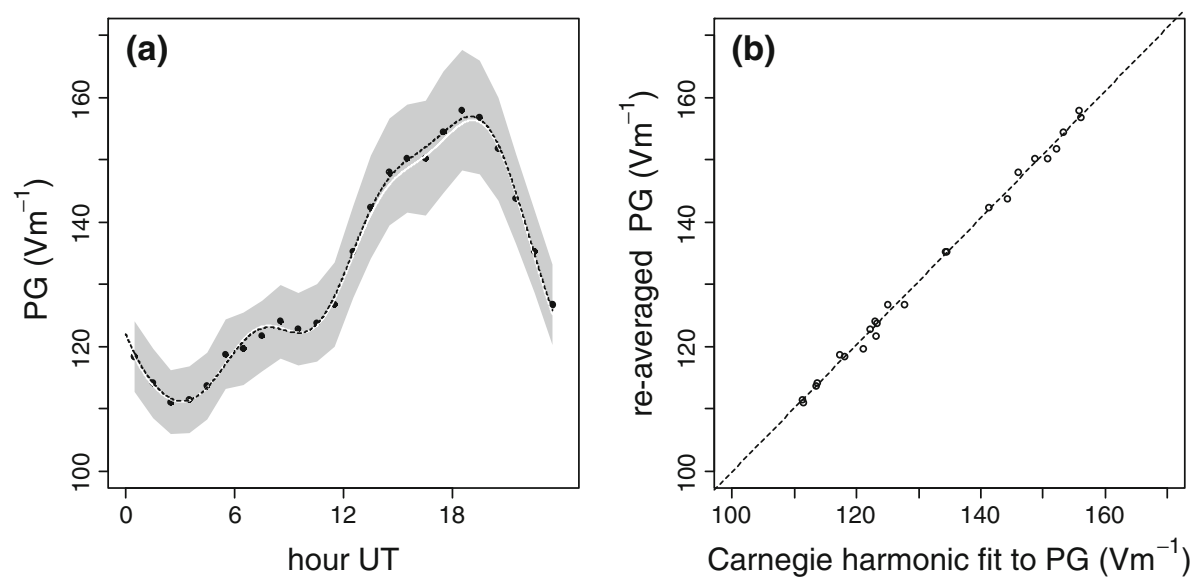

Fig. 6 a Annual mean values (points) of hourly PG re-calculated from the selected 82 undisturbed days of Cruise VII. The solid white line is the original fit from the Carnegie Institution's harmonic coefficients (CIW568, p. 136, Table 2) and the dotted line from a modern harmonic analysis fit to the hourly recalculated data. The shading shows the range of 1.96 standard errors on the mean, corresponding to a $95 \%$ confidence interval on the mean. b Hourly mean PG values calculated from the Carnegie Institution harmonic coefficients, evaluated for the midpoint of each hour, plotted against the re-calculated hourly mean PG values in a, with a least squares fit line added (gradient $1.00 \pm 0.01$, intercept $(-0.1 \pm 1.7) \mathrm{Vm}^{-1}$ )

respectively, with $\phi_{1}$ to $\phi_{4}$ the associated phase angles (in degrees). This harmonic fit to the annual data is, effectively, the "Carnegie curve", in that it is a representation of the continuous variation deduced to occur from the hourly observations.

Both the original ${ }^{24}$ annual fit using the Carnegie Institution harmonic coefficients and the harmonic fit recalculated from the data in ESM are plotted in Fig. 6a. The recalculated and original harmonic fits are virtually indistinguishable. As a further check, calculations of the hourly values from the original harmonic fit are compared with hourly means from re-averaging the transcribed data in Fig. $6 \mathrm{~b}$. The close agreement shows that original harmonic fitting represents the data extremely well, as determined by fitting a least squares line; this line has unit gradient and zero offset to within its standard errors. This consistency gives confidence in both the reliability of the transcription of the data, and, since the original and recalculated annual Fourier coefficients give almost identical results, the harmonic analysis.

As remarked earlier, the data can be grouped seasonally, and the original data analysis divided the data into northern hemisphere winter (November-December-January, NDJ), spring (February-March-April, FMA), summer (May-June-July, MJJ) and autumn (August-September-October, ASO). Harmonic coefficients were derived for the data selected according to these groups of months by Parkinson and Torreson (1931), which were also tabulated in Israël's text book on Atmospheric Electricity (Israël 1973). However, the coefficients were then updated in Carnegie Institution publication 568, published in 1946, and consequently, some of these coefficients (primarily the annual ones) differ from those of Table XVIII in Israël (1973). The close agreement of the 1946 CIW coefficients with those recalculated here using the transcribed original data (Fig. 6a) and the verification of their representation of the data (Fig. 6b) show that the later values represent the raw data correctly; using the CIW 568 coefficients for the annual average diurnal cycle

24 CIW568, p136, Table 2. 
Table 4 Coefficients obtained from harmonic analysis of the Cruise VII data, by season

\begin{tabular}{|c|c|c|c|c|c|c|c|c|c|c|c|}
\hline \multirow[t]{2}{*}{ Season } & \multicolumn{5}{|c|}{ Amplitude coefficients $\left(\mathrm{Vm}^{-1}\right)$} & \multicolumn{4}{|c|}{ Phase angle (degrees) } & \multicolumn{2}{|c|}{ Hour (UT) } \\
\hline & $A_{0}$ & $A_{1}$ & $A_{2}$ & $A_{3}$ & $A_{4}$ & $\phi_{1}$ & $\phi_{2}$ & $\phi_{3}$ & $\phi_{4}$ & Min & $\operatorname{Max}$ \\
\hline NDJ & 140.1 & 25.6 & 8.3 & 1.9 & 1.8 & 197.4 & 253.8 & 209.4 & 3.0 & 2.5 & 18.1 \\
\hline DJF & 147.8 & 26.2 & 6.3 & 1.3 & 2.1 & 200.5 & 257.6 & 190.1 & 345.0 & 3.1 & 17.7 \\
\hline JFM & 141.9 & 24.7 & 4.2 & 1.8 & 3.3 & 195.9 & 265.2 & 195.3 & 336.2 & 3.9 & 17.9 \\
\hline FMA & 139.4 & 21.5 & 3.7 & 2.3 & 3.1 & 197.2 & 267.2 & 182.1 & 328.9 & 3.6 & 17.2 \\
\hline MAM & 125.9 & 22.6 & 4.2 & 2.3 & 2.3 & 174.1 & 243.0 & 176.8 & 343.4 & 5.0 & 19.0 \\
\hline AMJ & 117.5 & 20.5 & 4.7 & 4.0 & 0.5 & 161.3 & 215.6 & 133.0 & 313.6 & 4.8 & 19.9 \\
\hline MJJ & 116.8 & 19.7 & 5.3 & 3.9 & 0.4 & 158.0 & 215.2 & 132.2 & 316.3 & 4.7 & 20.1 \\
\hline JJA & 102.5 & 10.8 & 12.8 & 6.1 & 1.3 & 148.3 & 167.5 & 194.1 & 86.7 & 3.3 & 22.2 \\
\hline JAS & 110.3 & 8.7 & 8.3 & 3.3 & 0.2 & 166.0 & 193.5 & 206.1 & 330.6 & 2.6 & 20.7 \\
\hline ASO & 119.4 & 13.6 & 7.0 & 2.9 & 0.6 & 180.6 & 206.4 & 206.4 & 326.5 & 2.8 & 19.9 \\
\hline SON & 126.4 & 17.5 & 7.4 & 2.3 & 1.1 & 192.0 & 241.9 & 201.9 & 331.6 & 1.7 & 18.6 \\
\hline OND & 138.9 & 24.1 & 8.8 & 2.1 & 1.2 & 197.8 & 252.0 & 206.9 & 4.9 & 1.8 & 18.1 \\
\hline Annual & 132.2 & 20.4 & 6.1 & 2.2 & 1.6 & 191.2 & 239.2 & 193.7 & 344.1 & 3.0 & 18.5 \\
\hline
\end{tabular}

(a) NDJ

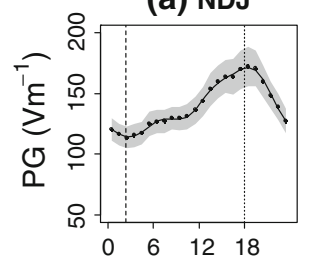

(e) DJF

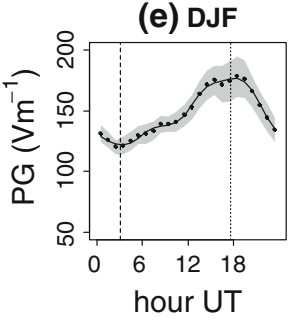

(b) FMA

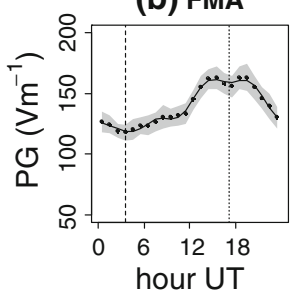

(f) MAM

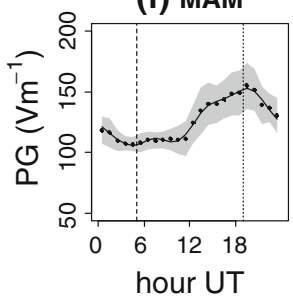

(c) MJJ

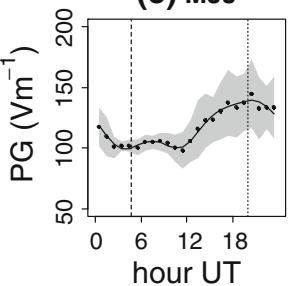

(g) JJA

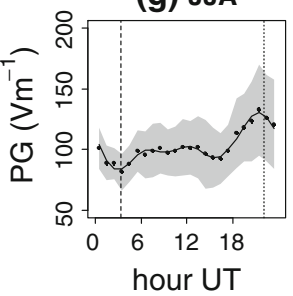

(d) ASO

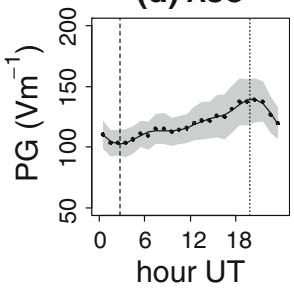

(h) SON

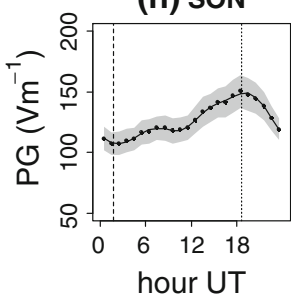

Fig. 7 Seasonal PG variations for original (a-d) and conventional (e-h) selections of months representing the northern hemisphere winter, spring, summer and autumn, from the 82 designated fair weather days. (Points give the mean hourly values, and the shading shows the range of 1.96 standard errors on the mean. Lines are calculated from the harmonic coefficients given in Table 4 . The vertical dashed and dotted lines mark the minimum and maximum times derived by the procedure described in the text.)

gives a mean value of $6 \mathrm{Vm}^{-1}$ less $^{25}$ than from the coefficients of Israël Table XVIII. The difference in phase from the two sets of coefficients is negligible $(<0.1 \mathrm{~h})$.

${ }^{25}$ This is apparent in the $A_{0}$ coefficient, which is alternatively $138 \mathrm{Vm}^{-1}$ (Israël 1973) and $132 \mathrm{Vm}^{-1}$ (CIW 568). 
For consistency, a recalculation of all the harmonic coefficients has been made from the data in the ESM, using the original definitions of the seasons, the conventional seasonal definitions (DJF, MAM, JJA and SON) and the remaining groups of 3 months. These recalculated coefficients (Table 4) allow the Carnegie curve to be calculated for any three consecutive months. Figure 7 compares the hourly PG data averaged using both seasonal definitions, showing also the recalculated harmonic fits. It is apparent that the limited sampling in the summer makes the curve's maximum and minimum less distinct statistically, but that the Fourier decomposition provides an effective representation in all seasons, within the standard error of the mean diurnal variation.

\subsection{Seasonal Variations}

The duration of Cruise VII of only about a year and its poor sampling of fair weather days during the northern hemisphere summer has led to difficulties in drawing conclusions from this data about seasonal variations in the PG. One approach to deriving the seasonal PG variation has been to include data from other cruises to provide further northern hemisphere summer information, although this brings with it questions about consistency of absolute calibration and selection of fair weather circumstances. Rycroft et al. (2008) combined the data from Cruises IV, V, VI and VII to provide more data in determining the change in the Carnegie curve in different seasons, but still found the maximum and minimum of the diurnal cycle barely statistically distinguishable during the summer. Adlerman and Williams (1996) combined the Carnegie data with measurements of another survey ship, the Maud, and concluded that the seasonal variation in PG showed a maximum in the northern hemisphere summer, coinciding with the known maximum in global lightning at that time. The harmonic analysis of Table 4 provides an alternative method for investigating characteristics of the annual variation, by considering seasonal variations in the Carnegie curve's phase.
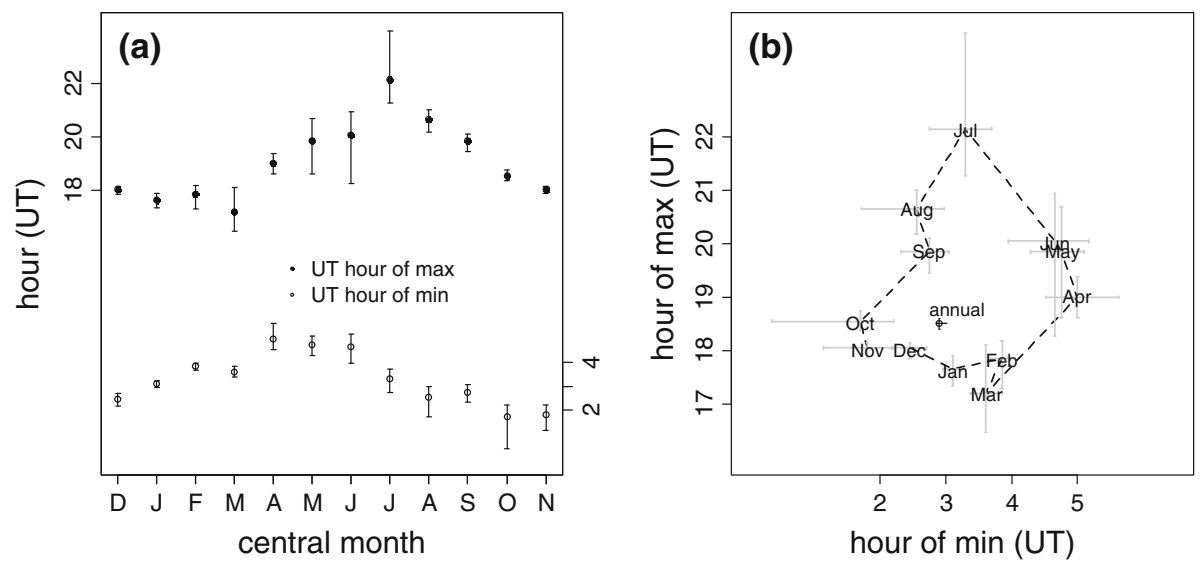

Fig. 8 a Variation in the time (in UT hours) of the maximum and minimum in the Carnegie curve, from Table 4, for 12 groups of 3 months running consecutively from November-December-January ("December)" to October-November-December ("November"). b Ellipse formed by plotting the Carnegie curve's time of minimum against the time of the maximum, in each of the groups of 3 months. The single point represents the annually averaged time of the maximum and minimum. (For both plots, error bars represent $95 \%$ confidence limits.) 
After selecting the data by season, some of the harmonic fits show increased ripple from the finite term Fourier representation over the annual case. Consequently, a more robust procedure has been used to determine the maximum and minimum times than to use the Fourier representation alone, which is subject to fluctuations. This method is to fit a cubic smoothing spline, from which the minimum and maximum values were derived. Table 4 shows that the maximum and minimum times in the Carnegie curve vary with season, as found for successive groups of 3-month periods. These variations are shown in Fig. 8, plotted against the central month of the each 3 month group. Error bars on the maximum and minimum times have been estimated by a Monte-Carlo procedure, in which the hourly PG values were varied to generate different realisations. The hourly PG values were chosen from a Gaussian distribution centred on the mean hourly value, with a width determined by each hour's standard error, after the contribution to the variation due to the diurnal cycle for the season concerned had first been removed. The multiple realisations were made to determine the $95 \%$ confidence range on the maximum and minimum times, but with values beyond $\pm 3 \mathrm{~h}$ from the central value discarded as out of range.

Figure 8a clearly illustrates a different seasonal phasing for the variations in the maximum and minimum hours. Comparing the left-hand side of the plot (northern hemisphere spring) with the middle part of the plot (northern hemisphere summer), the interval from minimum to maximum is greatest for northern hemisphere summer, somewhat suggestive of a contribution from the longer day lengths of the northern hemisphere summer. In surface PG measurements made at Vostok, Antarctica, Burns et al. (2005) found diurnal maxima of 2050UT for July-August and 1830UT for November-December, consistent with both the timings and seasonal change apparent in Table 4. The derived maximum and minimum times of the seasonal Carnegie curves are plotted against each other in Fig. 8b, together with the single point showing the maximum and minimum times of the annually averaged Carnegie curve. It is clear from this presentation of the data that variations of these times approximately describe an ellipse, due to a larger variation in the time of the maximum than the minimum. The spread clearly varies with the sampling (this makes the "May" and "June" values indistinguishable, for example), but, because some symmetry is still apparent, and no appreciable hysteresis is evident, it seems likely that these parameters derived from the Carnegie curve represent seasonal variations in the global circuit.

\subsection{Latitudinal Variation}

Analysis of the PG data from the earlier cruises' measurements indicated that the PG was generally around its least at the equator and showed a general increase with latitude north and south. ${ }^{26}$ These findings $^{27}$ for Cruises IV and VI are presented in Fig. 9a, b, respectively, with the median values for each latitude band added. From these, evidence for the latitude effect is suggestive, but marginal. The Cruise VII data provide a further opportunity for investigating the spatial variation of PG, but, because of the short duration of Cruise VII, variations of PG with latitude will again be combined with seasonal variations also occurring. The mean daily PG for the 82 selected undisturbed days of Cruise VII is plotted against latitude, in Fig. 9c. Clearly, the PG was reduced as the ship passed through

\footnotetext{
$\overline{{ }^{26}}$ Subsequent work has indicated that cosmic ray ionisation varies spatially with geomagnetic latitude, with least ionisation occurring at the magnetic equator (e.g., Bazilevskaya et al. 2008). The geomagnetic effect on cosmic ray ionisation also influences the PG at the surface, and hence, a spatial variation is caused.

${ }^{27}$ CIW175v3, p403.
} 

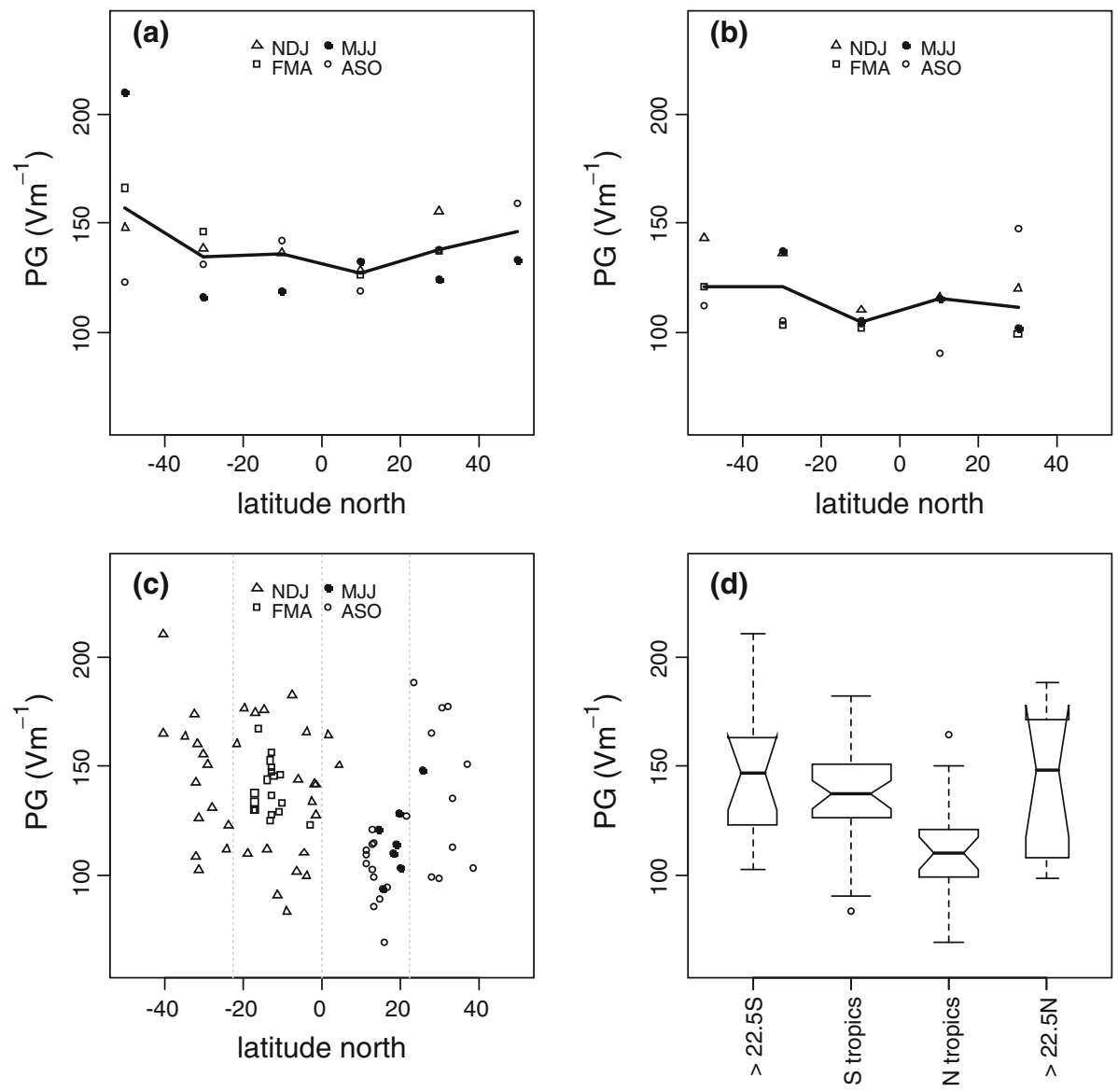

Fig. 9 Variation of potential gradient with latitude, as observed on Carnegie Cruises IV, VI, and VII. a shows data from Cruise IV and $\mathbf{b}$ data from Cruise VI, where the points are the mean values reported in $20^{\circ}$ latitude bands (from Table 81, CIW175v3, p403), with the seasons (NDJ, FMA, MJJ, ASO) used in the original analysis also identified. Solid lines have been plotted through the medians of the values. c Mean daily PG on the 82 undisturbed days of Cruise VII plotted against latitude, grouped by the same seasons as a and b. d Boxplots of the Cruise VII data points from c divided into latitudes more southerly than $22.5^{\circ} \mathrm{S}$, between $22.5^{\circ} \mathrm{S}$ and the equator, north of the equator to $22.5^{\circ} \mathrm{N}$, and more northerly than $22.5^{\circ} \mathrm{N}$. (Thickened horizontal lines indicate the medians with notches indicating $95 \%$ confidence limits, and the boxes show the inter-quartile range of the data.)

the northern tropical regions, but the different latitudes are not equally sampled across all seasons, and so a statistical comparison is necessary. Figure $9 \mathrm{~b}$ represents the same data using boxplots, which provide a statistical test of changes in the median, shown as a thickened line in the centre of the boxplot. If a median lies outside the range of the notches on another median, the two medians can be regarded as different. With this data, this is the only case for the northern extra-tropics and northern tropical regions. A further statistical test (Kolmogorov-Smirnov) on the days of the year concerned with these two cases indicates that a null hypothesis of the measurement days in the two regions being drawn from the same distribution of days cannot be rejected. This is, therefore, not inconsistent 


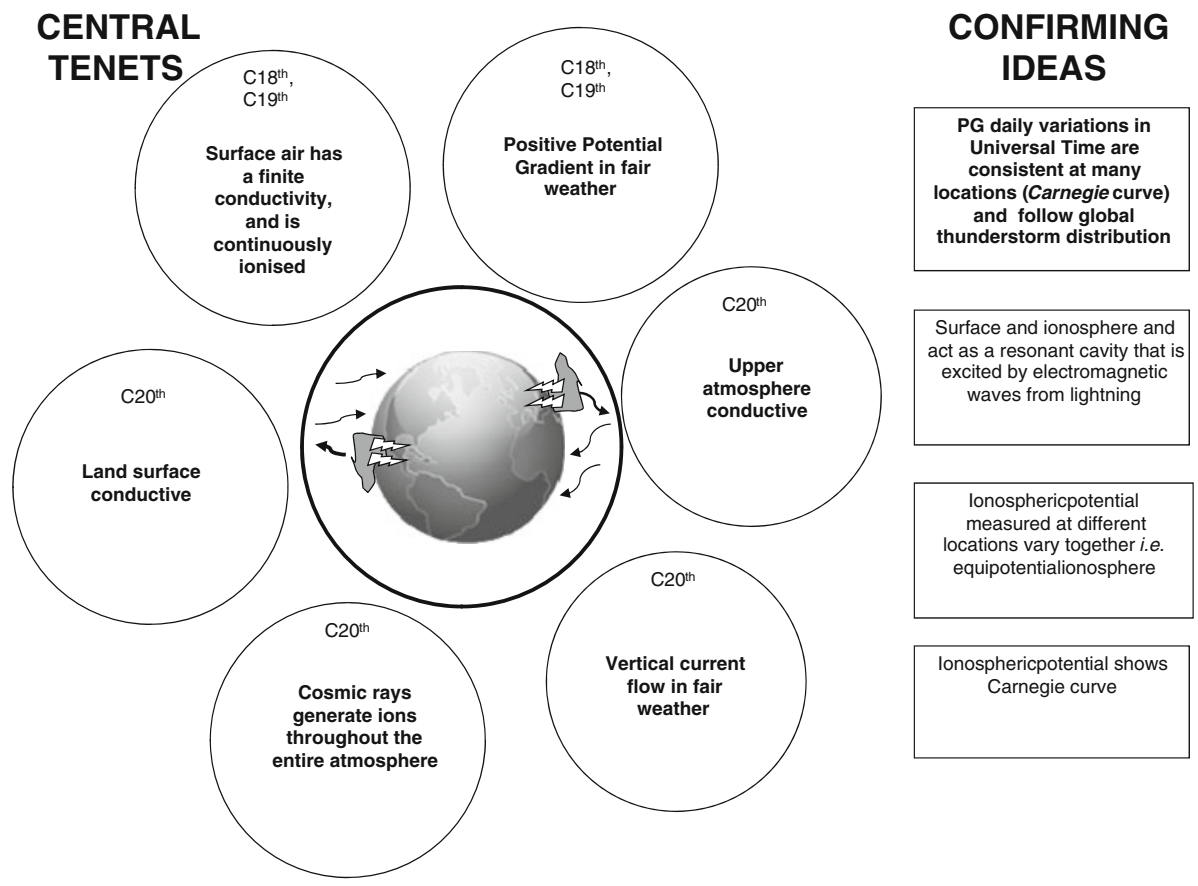

Fig. 10 Development of the global circuit concept, adapted from Aplin et al. (2008) where original references are also given. The development follows the historical establishment of Central tenets, with the conceptual picture proposed subsequently supported by Confirming ideas

with the conclusion from the earlier cruises that PG variations may include a latitudinal contribution.

\section{Historical Importance}

As mentioned in the introduction, a major early motivation for studying atmospheric electricity was explaining the sustained electric field apparent in fair weather. An important challenge to the prevailing perspective occurred around 1900, when C. T. R. Wilson and Elster and Geitel established that atmospheric air was continuously ionised, pointing to the importance of current flow, rather than a solely electrostatic situation (Simpson 1906). Subsequently, in 1920, Wilson proposed (Wilson 1921) that currents in the atmosphere could be maintained by thunderstorms and shower clouds. In support of this hypothesis, good agreement was later demonstrated between the Carnegie curve obtained in the early cruises and the diurnal variation thunderstorm area by Whipple in 1929 (Whipple 1929), also recognised by Wilson (Wilson 1929). These developments provide some important context for the Carnegie measurements.

Aplin et al. (2008) discuss the progression of findings and ideas leading to the concept of a global circuit, in which currents sustained by disturbed weather regions are coupled through the conductivity of the ionosphere and planetary surface to fair weather regions elsewhere. This is summarised in Fig. 10. The close agreement between Carnegie curve 


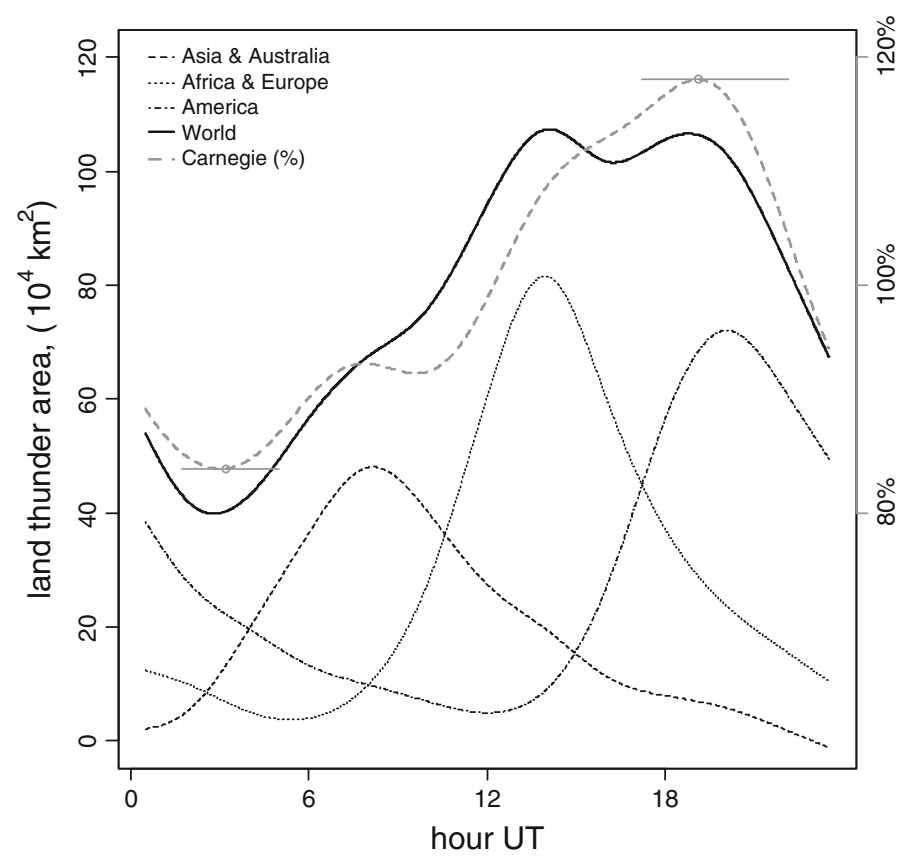

Fig. 11 Comparison between total land thunderstorm area (thick solid line, left-hand axis) with its regional contributions, as originally presented by Whipple and Scrase (1936), and the Carnegie curve (grey dashed line, right-hand axis) calculated as relative values from annual coefficients of Table 4 . The seasonal range in timing of the Carnegie curve's maximum and minimum is shown by horizontal bars about their annual mean values

and the classical estimates of thunderstorm area, as originally determined from the thunderstorm area data compilation of Brooks (1925) by Whipple (Whipple 1929; Whipple and Scrase 1936), provides one of the "Confirming Ideas" for the conceptual model of the global atmospheric electric circuit.

The Carnegie diurnal variation as a confirming idea is now briefly considered further, firstly in terms of the original thunderstorm area relations, and secondly in terms of further confirmatory ideas.

\subsection{Persistence and the Thunderstorm Area Correlation}

Figure 11 shows the original thunderstorm data of Whipple and Scrase (1936), overplotted with the (annual) Carnegie curve calculated from the harmonic coefficients of Table 4. The well-known close correlation between the classical global thunderstorm area and the Carnegie curve is evident. It has long been recognised that these early statistics would underestimate oceanic storms (e.g., Israël 1973), and indeed, recent work (Mach et al. 2011) has shown that a better fit to the Carnegie curve can be obtained by including oceanic storms with and without lightning (shower clouds) and shower clouds over land, because of the additional electrification from shower clouds (Liu et al. 2009).

For the relationship in Fig. 11, the linear correlation coefficient $r$ between the 24 hourly data values of PG and global thunderstorm areas (Table 5) is $r=0.94$. Whilst this result seems very unlikely to have arisen by chance, assessment of this correlation's significance 
Table 5 Carnegie curve PG and land areas of thunderstorms from Whipple and Scrase (1936)

\begin{tabular}{|c|c|c|c|c|c|}
\hline \multirow[t]{2}{*}{ Hour (UT) } & \multirow[t]{2}{*}{$\mathrm{PG}\left(\mathrm{Vm}^{-1}\right)$} & \multicolumn{4}{|c|}{ Area $\left(10^{4} \mathrm{~km}^{2}\right)$} \\
\hline & & World & Asia & Africa & America \\
\hline 0.5 & 118.1 & 54 & 2 & 12 & 38 \\
\hline 1.5 & 113.7 & 45 & 7 & 9 & 31 \\
\hline 2.5 & 111.4 & 40 & 12 & 7 & 25 \\
\hline 3.5 & 111.4 & 41 & 19 & 5 & 21 \\
\hline 4.5 & 113.5 & 46 & 26 & 4 & 18 \\
\hline 5.5 & 117.3 & 53 & 32 & 4 & 15 \\
\hline 6.5 & 121.2 & 60 & 38 & 6 & 12 \\
\hline 7.5 & 123.2 & 65 & 42 & 11 & 11 \\
\hline 8.5 & 123.0 & 69 & 43 & 18 & 9 \\
\hline 9.5 & 122.2 & 73 & 41 & 28 & 8 \\
\hline 10.5 & 123.3 & 80 & 37 & 40 & 6 \\
\hline 11.5 & 127.7 & 89 & 33 & 52 & 5 \\
\hline 12.5 & 134.5 & 99 & 27 & 62 & 5 \\
\hline 13.5 & 141.2 & 106 & 22 & 68 & 7 \\
\hline 14.5 & 146.0 & 107 & 18 & 69 & 12 \\
\hline 15.5 & 148.6 & 103 & 14 & 64 & 21 \\
\hline 16.5 & 150.7 & 102 & 11 & 57 & 34 \\
\hline 17.5 & 153.3 & 104 & 9 & 48 & 49 \\
\hline 18.5 & 155.8 & 106 & 7 & 39 & 63 \\
\hline 19.5 & 156.1 & 106 & 6 & 30 & 71 \\
\hline 20.5 & 152.2 & 100 & 4 & 23 & 71 \\
\hline 21.5 & 144.3 & 90 & 3 & 17 & 66 \\
\hline 22.5 & 134.4 & 79 & 1 & 11 & 58 \\
\hline 23.5 & 125.1 & 67 & 0 & 5 & 50 \\
\hline
\end{tabular}

Annual PG values calculated using Table 4. Thunderstorms areas individually interpolated from Fig. 9 of Whipple and Scrase (1936)

depends on identifying the independent degrees of freedom in the data. Within the global circuit, several physical timescales [e.g., the lifetime of thunderstorms, the duration of regional surface heating and the electrical time constant of the Earth ionosphere system (Rycroft et al. 2000)], exist which suggest that adjacent hourly values are unlikely to be statistically independent. Evaluating the autocorrelation of the Carnegie curve shows persistence to about $4 \mathrm{~h}$, indicating that there are only about 5 potentially independent values in the 24 points. This greatly reduces the significance of the correlation between the thunderstorm area and the Carnegie curve, as, although choosing just the pairs of values for 0030UT, 0530UT, 1030UT, 1530UT and 2030UT still gives a substantial linear correlation $r=0.94$, the probability $p$ that this has arisen by chance becomes $p=0.02$. The slightly more pessimistic case represented by assuming $5 \mathrm{~h}$ persistence (choosing 0030UT, 0630UT, 1230UT and 1830UT) gives $r=0.91$, with $p=0.09$, outside the conventional range accepted for statistical significance of $p<0.05$.

A less arbitrary alternative approach to evaluating the significance in time series with persistence is to use a Monte-Carlo method, randomising the data whilst maintaining statistical properties of the persistence in Fourier space, to evaluate how often the 
Fig. 12 PG measurements from UK sites obtained during the last half-century. Points show (a) average diurnal variation from 1968 to 1984 for Lerwick, Shetland (December fair weather values only) and (b) average diurnal variation from 2007 to 2011 for Reading (DecemberJanuary-February, values from 0 to $250 \mathrm{Vm}^{-1}$ only). In both cases, the Carnegie curve harmonic fit for DecemberJanuary-February is normalised to the mean and overplotted (solid thin line)
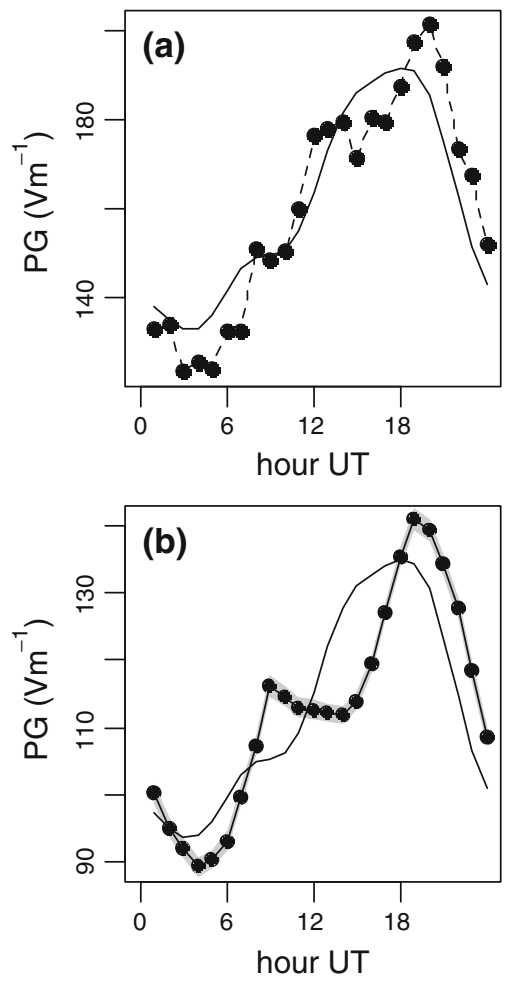

correlation observed actually does occur by chance (e.g., Ebisuzaki 1997). Using this approach, $p<0.01$, and hence, the correlation apparent in Fig. 11 so central to the global circuit concept is unlikely to have arisen by chance.

\subsection{Subsequent Diurnal Variation Determinations}

The enduring importance of the Carnegie curve is that it describes a global diurnal variation which is still found in modern atmospheric electricity measurements. Since the Carnegie cruises, observations demonstrating a Carnegie curve variation within the atmospheric system have continued. For example, the discovery of a similar diurnal variation in the ionospheric potential (Mühleisen 1977; Markson 1986) provided yet another "Confirming Idea" for the global circuit. The cruises of the Meteor in the 1960s (Budyko 1970; Harrison 2004b) showed continued Carnegie curve variations, as have measurements in Antarctica during 1998-2002 (Burns et al. 2005). Land sites require more averaging for the Carnegie curve to emerge over local variations, and averaged diurnal cycles from measurement sites at Reading and Lerwick, Scotland, are shown in Fig. 12. The measurements at Lerwick Observatory in Shetland have also consistently shown Carnegie-like variations from 1930s to 1970s (Harrison 2003), but with additional responses in phase and amplitude attributed to the El Niño-Southern Oscillation, ENSO $^{28}$ (Harrison et al. 2011).

${ }^{28}$ Reconstructions of ocean temperature anomalies do not indicate appreciable ENSO effects in 1928-1929, during Cruise VII (e.g., http://www.cgd.ucar.edu/cas/catalog/climind/TNI_N34/index.html\#Sec5). 


\section{Conclusions}

The universal diurnal variation in atmospheric electricity represented by the Carnegie curve, now apparent in many of the variables of atmospheric electricity, is clearly one of the fundamental oscillations of the atmospheric system. Its early twentieth-century discovery provides thoroughly investigated reference information against which subsequent changes can be assessed, particularly for the annually averaged and northern hemisphere winter diurnal variations. Analysis of the shape of the curve, in particular the phasing of its maximum and minimum, yields a little more information, as both the times of the curve's minimum and maximum vary seasonally, lying around an ellipse (Fig. 8). The time of the minimum of the Carnegie curve varies approximately between the equinoxes, whereas the variation in the time of the maximum, which is greater, occurs approximately between the solstices. Comparison with the classical thunderstorm area data in Fig. 11 suggests that changes in the time of the maximum occur during changes in the relative contributions of American and African thunderstorms between the southern hemisphere and northern hemisphere summers, but this simple interpretation ignores the additional contributions of electrified shower clouds (Liu et al. 2009).

Finally, the ocean PG measurements which underpin the Carnegie curve were selfevidently obtained as a result of great experimental ingenuity and diligence, alongside the development of pioneering instrumentation in the pre-electronic era. That the analysis undertaken in the early 1930s can be replicated almost exactly is a further tribute to the care with which the Carnegie Institution scientists reported, tabulated and computed their results.

Acknowledgments The modern study of atmospheric electricity owes a great debt to the Carnegie scientists who undertook the pioneering cruises described, and I am grateful to the Carnegie Institution of Washington for permission to use material. Keri Nicoll and Denise Hargreaves helped considerably with the data transcription and checking, and Andrew Lomas kindly generated Fig. 2a. David Marshall (University of Oxford) and Walter Munk (Scripps Institution of Oceanography) provided helpful discussion of the Carnegie's oceanographic importance.

\section{References}

Adlerman EJ, Williams ER (1996) Seasonal variation of the global electric circuit. J Geophys Res 101(D23):29679-29688

Aplin KL (2005) Aspirated capacitor measurements of air conductivity and ion mobility spectra. Rev Sci Instrum 76:104501. doi:10.1063/1.2069744

Aplin KL, Harrison RG, Rycroft MJ (2008) Investigating Earth's atmospheric electricity: a role model for planetary studies. Space Sci Rev 137:11-27. doi:10.1007/s11214-008-9372-x

Ault JP (1927) Oceanographic investigations on the next cruise of the Carnegie, 1927. Bull Natl Res Counc 61:198-204

Bauer LA, Peters WJ, Fleming JA, Ault JP, Swann WFG (1917) Ocean magnetic observations 1905-1916 and reports on special researches, vol 3. Researches of the Department of Terrestrial Magnetism, Carnegie Institution of Washington Publication 175, pp 378-392

Bazilevskaya GA, Usoskin IG, Flückiger EO, Harrison RG, Desorgher L, Bütikofer RB, Krainev MB, Makhmutov VS, Stozhkov YI, Svirzhevskaya AK, Svirzhevsky NS, Kovaltsov GA (2008) Cosmic ray induced ion production in the atmosphere. Space Sci Rev 137:149-173. doi:10.1007/s11214-0089339-y

Bennett AJ, Harrison RG (2006) In situ calibration of atmospheric air conductivity measurements. Rev Sci Instrum 77:016103 
Brooks CEP (1925) The distribution of thunderstorms over the globe. Geophys Mem Met Off Lond 3(24):147-164

Budyko MI (1970) Results of observations of atmospheric electricity (The World Network, Additional Issue 1965-1969). USSR Chief Administration of the Hydro-Meteorological Service, Leningrad

Burns GB, Frank-Kamenetsky AV, Troshichev OA, Bering EA, Reddell BD (2005) Interannual consistency of bi-monthly differences in diurnal variations of the ground-level, vertical electric field. J Geophys Res 110:D10106. doi:10.1029/2004JD005469

Cobb WE, Wells HJ (1970) The electrical conductivity of oceanic air and its correlation to global atmospheric pollution. J Atmos Sci 27:814-817

Ebisuzaki W (1997) A method to estimate the statistical significance of a correlation when the data are serially correlated. J Clim 10:2147-2153

Everett JD (1868) Results of observations of atmospheric electricity at Kew Observatory, and at Kings College, Windsor, Nova Scotia. Philos Trans R Soc Lond 158:347-361

Gerdien H (1905) Ein neuer Apparat zur Messung der elektrischen Leitfähigkeit der Luft. Nachrichten von der Gesellschaft der Wissenschaften zu Göttingen, Mathematisch-Physikalische Klasse, pp 240-251

Hackmann W (1994) Sir Francis Ronalds' electric observatory. Bull Sci Instrum Soc 43:27-28

Harrison RG (2003) Twentieth century atmospheric electrical measurements at the observatories of Kew, Eskdalemuir and Lerwick. Weather 58:11-19

Harrison RG (2004a) The global atmospheric electrical circuit and climate. Surv Geophys 25(5-6):441-484. doi: $10.1007 / \mathrm{s} 10712-004-5439-8$

Harrison RG (2004b) Long term measurements of the global atmospheric electric circuit at Eskdalemuir, Scotland, 1911-1981. Atmos Res 70(1):1-19. doi:10.1016/j.atmosres.2003.09.007

Harrison RG (2011a) Fair weather atmospheric electricity. J Phys: Conf Ser 301:012001. doi: 10.1088/1742-6596/301/1/012001

Harrison RG (2011b) The cloud chamber and CTR Wilson's legacy to atmospheric science. Weather 66(10):276-279. doi:10.1002/wea.830

Harrison RG, Bennett AJ (2007) Cosmic ray and air conductivity profiles retrieved from early twentieth century balloon soundings of the lower troposphere. J Atmos Sol-Terr Phys 69(4-5):515-527. doi: 10.1016/j.jastp.2006.09.008

Harrison RG, Ingram WJ (2005) Air-earth current measurements at Kew, London, 1909-1979. Atmos Res 76(1-4):49-64. doi:10.1016/j.atmosres.2004.11.022

Harrison RG, Joshi M, Pascoe K (2011) Inferring convective responses to El Niño with atmospheric electricity measurements at Shetland. Environ Res Lett 6:044028. http://iopscience.iop.org/17489326/6/4/044028/

Israël H (1973) Atmospheric electricity vol. 2 (fields, charges, currents) (Problems of cosmic physics vol. 29). Israel Program for Scientific Translations, Jerusalem

Lemonnier LG (1752) Observations sur l'electricite de air. Mem Acad Sci 2:233

Liu C, Williams ER, Zipser EJ, Burns G (2009) Diurnal variations of global thunderstorms and electrified shower clouds and their contribution to the global electrical circuit. J Atmos Sci 67:309-323

Mach DM, Blakeslee RJ, Bateman MG (2011) Global electric circuit implications of combined aircraft storm electric current measurements and satellite-based diurnal lightning statistics. J Geophys Res 116:D05201. doi:10.1029/2010JD014462

Markson R (1986) Tropical convection, ionospheric potentials and global circuit variation. Nature 320:588-594

Mauchly SJ (1921) Note on the diurnal variation of the atmospheric electric potential gradient. Phys Rev 18:161-162

Mauchly SJ (1923) On the diurnal variation of the potential gradient of atmospheric electricity. Terr Magn 28:61-81

Mühleisen RP (1977) The global circuit and its parameters. In: Dolezalek H, Reiter R (eds) Electrical processes in atmospheres. Dr. Dietrich Steinkopff Verlag, Darmstadt, pp 467-476

Nicoll KA (2012) Measurements of atmospheric electricity aloft. Surv Geophys. doi:10.1007/s10712-0129188

Owens MJ, Usoskin I, Lockwood M (2012) Heliospheric modulation of galactic cosmic rays during grand solar minima: past and future variations. Geophys Res Lett 39:L19102. doi:10.1029/2012GL053151

Parkinson WC, Torreson OW (1931) The diurnal variation of the electric potential of the atmosphere over the oceans. UGGI (Sect Terr Magn Elec) Bull 8:340-341

Read J (1792) A meteorological journal, principally relating to atmospheric electricity; kept at Knightsbridge, from the 9th of May, 1790, to the 8th of May, 1791. Philos Trans R Soc Lond 82:225-256 
Rodger CJ, Werner S, Brundell JB, Lay EH, Thomson NR, Holzworth RH, Dowden RL (2006) Detection efficiency of the VLF World-Wide Lightning Location Network (WWLLN): initial case study. Ann Geophys 24:3197-3214

Ronalds F (1847) On photographic self-registering meteorological and magnetical instruments. Philos Trans R Soc Lond 137:111-117

Rycroft MJ, Israelsson S, Price C (2000) The global atmospheric electric circuit, solar activity and climate change. J Atmos Sol-Terr Phys 62:1563-1576

Rycroft MJ, Harrison RG, Nicoll KA, Mareev EA (2008) An overview of Earth's global electric circuit and atmospheric conductivity. Space Sci Rev 137:83-105. doi:10.1007/s11214-008-9368-6

Simpson GC (1906) Atmospheric electricity in high latitudes. Philos Trans R Soc A 205:61-97

Simpson GC, Wright CS (1911) Atmospheric electricity over the ocean. Proc R Soc Lond A 85(577):175-199

Thomson W (1859) Report of the 29th meeting. British Association for the Advancement of Science, Aberdeen

Torreson OW, Parkinson WC, Gish OH, Wait GR (1946) Ocean atmospheric-electric results (Scientific Results of Cruise VII of the Carnegie during 1928-1929 under command of Captain J. P. Ault, vol 3). Researches of the Department of Terrestrial Magnetism. Carnegie Institution of Washington Publication, vol 568

Whipple FJW (1929) On the association of the diurnal variation of the electric potential gradient in fine weather with the distribution of thunderstorms over the globe. Q J R Meteorol Soc 55:351-361

Whipple FJW, Scrase FJ (1936) Point discharge in the electric field of the Earth. Geophys Mem Met Off Lond 68:1936

Wilson CTR (1906) On the measurement of the Earth-air current and on the origin of atmospheric electricity. Proc Camb Philos Soc 13(6):363-382

Wilson CTR (1921) Investigations on lightning discharges and the electric field of thunderstorms. Philos Trans A 221:73-115

Wilson CTR (1929) Some thundercloud problems. J Frankl Inst 208:1-12 